\title{
Tuning of the Molecular Properties of Polybenzimidazole by Copolymerization
}

Arindam Sannigrahi, Dhamodaran Arunbabu, R. Murali Sankar and

\author{
Tushar Jana ${ }^{*}$ \\ School of Chemistry \\ University of Hyderabad \\ Hyderabad, India \\ Tel: (91) 4023134808 \\ Fax: (91) 4023012460 \\ E-mail: tjsc@uohyd.ernet.in \\ (* To whom correspondence should be addressed)
}

Supporting Information 


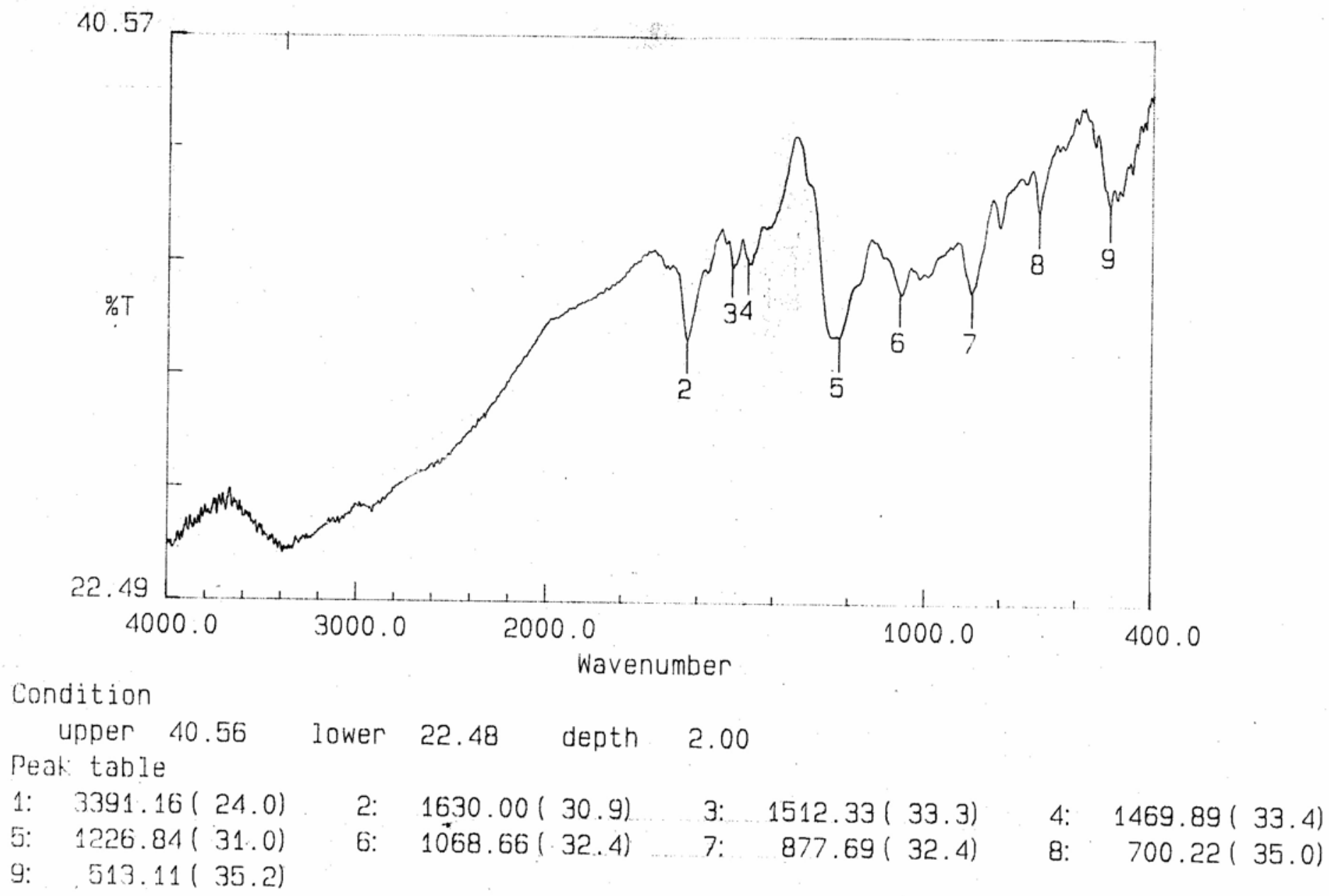

Supp. Figure 1: FT - IR spectrum of oligomer isolated after 2 hours of $100 \%$ para PBI hompolymerization at $190^{\circ} \mathrm{C}$. 


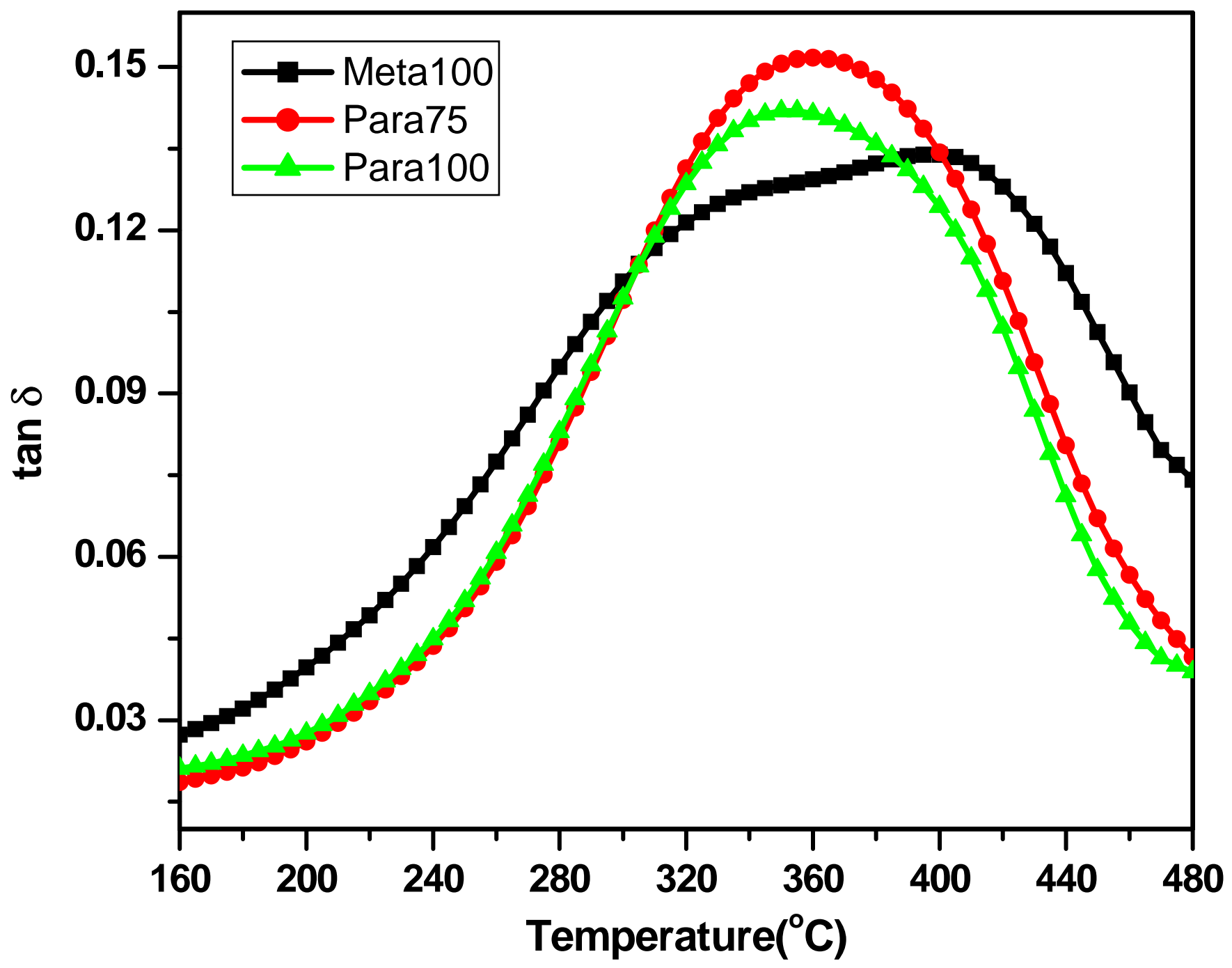

Supp. Figure 2: Mechanical property $(\tan \delta)$ vs. temperature plots of indicated copolymers as obtained from DMA analysis. Copolymer films of $25 \times 5 \times 0.04 \mathrm{~mm}$ dimension was used for the mechanical study on the film tension clamp of a dynamical mechanical analyzer (model Q 800 of TA instruments). 